\title{
O ESTADO DE EXCEÇÁO E A REVISÃO JUDICIAL: A ATUAÇÃO DAS CORTES CONSTITUCIONAIS NA PROTEÇÃO DOS DIREITOS FUNDAMENTAIS
}

\author{
THE STATE OF EXCEPTION AND THE JUDICIAL REVIEW: \\ THE ROLE OF CONSTITUTIONAL COURTS IN THE \\ PROTECTION OF FUNDAMENTAL RIGHTS
}

\author{
DEOMAR DA ASSENÇÃO AROUCHE JUNIOR ${ }^{1}$ \\ DELMO MATTOS DA SILVA ${ }^{2}$ \\ ROBERTO CARVALHO VELOSO ${ }^{3}$
}

\section{RESUMO}

A utilização de medidas excepcionais, por parte de governos, sempre foi objeto de controvérsia em razão de sua legitimidade. À vista disso, este artigo tem como objetivo analisar tal tema, adotando como referencial teórico os estudos de Giorgio Agamben. Discorre-se, inicialmente, sobre as funções e características do novo constitucionalismo desenvolvido no período pós-guerra e o reconhecimento da força normativa da Constituição. Após isso, por meio do método dedutivo, partindo das principais premissas colocadas pelos teóricos estudados, analisam-se situações de exceção ocorridas nos Estados Unidos e na Colômbia, destacando as justificativas e medidas de execução. A escolha por esses países ocorreu em virtude de terem vivenciado um ciclo completo com a decretação e execução de medidas excepcionais, até o questionamento perante as respectivas cortes constitucionais acerca da constitucionalidade dessas medidas. Diante disso, analisa-se como as cortes constitucionais atuaram frente a esses casos, principalmente no tocante à constitucionalidade da própria decretação do estado de exceção, bem como das medidas executórias. Por fim, analisa-se o teor dessas decisões, especialmente o tratamento dado a casos que resultaram em restrições a direitos fundamentais básicos.

Palavras-chave: Estado de exceção. Jurisdição constitucional. Controle de constitucionalidade. Direitos fundamentais.

1 Possui graduação em Direito pela Universidade Federal do Maranhão (2005). Especialização em Direito Constitucional pelo Uniceuma (2008). Mestrando do Programa de Pós-Graduação em Direito e Instituições do Sistema de Justiça da Universidade Federal do Maranhão (UFMA). Juiz Federal Substituto. ORCID iD: https://orcid.org/0000-0002-8021-4038. E-mail: deomar_arouchejr@hotmail.com.

2 Doutor em Filosofia pela UFRJ. Professor colaborador no Programa de Pós-graduação em Direito e Instituições do Sistema de Justiça pela UFMA. Pesquisador FAPEMA/CNPq. ORCID iD: https://orcid.org/0000-0002-9074-2192. E-mail: delmomattos@hotmail.com.

3 Doutor em Direito pela Universidade Federal de Pernambuco (2008), Mestre em Direito pela Universidade Federal de Pernambuco (2002), Coordenador do Mestrado em Direito e Instituições do Sistema de Justiça da UFMA, Juiz Federal, Ex-presidente da Ajufe. ORCID iD: https://orcid.org/0000-0002-7477-6675. E-mail: velosorc@uol.com.br. 
The use of exceptional measures by governments has always been the subject of controversy due to its legitimacy. In view of this, this article aims to analyze this theme, using as a theoretical reference the studies of Giorgio Agamben. It discusses initially the functions and characteristics of the new constitutionalism developed in the post-war period and the recognition of the normative force of the Constitution. After that, using the deductive method, starting from the main premises made by the studied theorists, it is analyzed situations of exception that occurred in the United States and Colombia, with an emphasis on justifications and measures of execution. These countries were chosen because they experienced a complete cycle with the enactment and execution of exceptional measures, until questioning before the respective constitutional courts about the constitutionality of those measures. Therefore, it is analyzed how the Constitutional Courts acted in these cases, especially with regard to the constitutionality of the enactment of the state of exception as well as of the enforcement measures. Finally, it is analyzed the content of these decisions, especially the treatment given to cases that resulted in restrictions on basic fundamental rights.

Keywords: State of exception. Constitutional jurisdiction. Judicial review. Fundamental rights.

\section{INTRODUÇÃO}

Este artigo tem como objetivo analisar as principais concepções teóricas acerca do estado de exceção, bem como sua aplicação em situações reais da história recente. Para tanto, investiga-se a utilização de medidas excepcionais nos Estados Unidos e na Colômbia com foco na análise de decisões proferidas pelas cortes constitucionais desses países no exercício de controle de constitucionalidade. Nesse contexto, por meio do método dedutivo, analisa-se a forma de atuação do Poder Judiciário desses países, frente a situações excepcionais vivenciadas em momentos de crise nas últimas décadas.

Como ponto de partida, discorre-se acerca das novas funções atribuídas às cortes constitucionais no papel de interpretar e de aplicar as normas constitucionais por meio dos modernos métodos de interpretação constitucional. Verificou-se a atuação das cortes à luz do dever de zelar pela manutenção da ordem democrática fundada nos valores constitucionais garantidores dos direitos fundamentais.

Na sequência, utilizando como referencial teórico os estudos de Giorgio Agamben sobre o Estado de Exceção, discorre-se sobre as principais características do instituto, bem como a problemática relacionada à legitimidade da sua utilização. Nesse ponto, enfatizam-se as críticas do autor italiano especialmente no que diz respeito à subjetividade na determinação das razões invocadas para a decretação de medidas de exceção.

Entre as várias críticas que faz ao instituto, Agamben recorda que as medidas de exceção geralmente consistem na atribuição de poderes excepcionais ao governante, o que implica o enfraquecimento dos pilares democráticos. 0 autor enfatiza que a medida resulta na restrição a direitos fundamentais e no cerceamento da atuação dos demais poderes. Aduz, além disso, que a justificativa para a adoção de tais medidas acaba por não ter nenhum tipo de controle ou verificação, dependendo apenas da vontade do governante.

O autor justifica as suas afirmações com vários exemplos em que medidas excepcionais, que deveriam ser transitórias, acabaram por se tornar definitivas, ensejando a deterioração do Estado Democrático de Direito. Em contrapartida, há corrente que entende a necessidade 
de aplicar medidas excepcionais restritivas como uma forma de proteção às instituições democráticas em situações de instabilidade.

A opção por analisar os casos da Colômbia e dos Estados Unidos ocorreu por serem países democráticos que utilizaram medidas de exceção, com severas restrições a direitos fundamentais, sob a alegação de enfrentarem ameaças à segurança nacional. Diante disso, tendo em vista que medidas de exceção ainda são eventualmente utilizadas e que, em alguns casos, estão, inclusive, previstas nas constituições, busca-se analisar, neste artigo, a forma como essas cortes enfrentaram as questões relacionadas ao tema. Ante esse cenário, analisam-se os resultados de ações que questionavam a constitucionalidade das medidas executórias decorrentes da situação excepcional vivenciada naquele momento.

Verificou-se que, em maior ou menor extensão, tanto a corte colombiana como a norte-americana consideraram constitucionais algumas medidas restritivas de direitos fundamentais e outras não. De um modo geral, foi possível constatar que, embora ambas admitam medidas dessa natureza, ressaltaram de forma clara que nenhum ato de governo praticado na vigência de uma situação excepcional está imune ao controle de constitucionalidade do Poder Judiciário.

Ao final, realiza-se, no presente artigo, uma breve análise de medidas de exceção decretadas em alguns países por conta da pandemia da Coronavirus Disease 2019 (Covid-19) e suas eventuais consequências para o Estado Democrático de Direito.

\section{A INTERPRETAÇÃO E A FORÇA NORMATIVA DA CONSTITUIÇÃO}

Tradicionalmente, hermenêutica significa teoria ou arte da interpretação e compreensão de textos, cujo principal objetivo é descrever como se dá o processo interpretativo-compreensivo ainda em seu sentido tradicional. Comporta, também, uma dimensão prescritiva, na medida em que, por meio desse processo descritivo, procura estabelecer um conjunto mais ou menos coerente de regras e métodos para se interpretar e compreender corretamente os mais diversos textos legais (STRECK, 2014).

Nesse sentido, de acordo com Streck (2014, p. 345), a norma constitucional "passa a ser, em toda a sua substancialidade, o topos hermenêutico que conformará a interpretação do restante do sistema jurídico". Entretanto, a Constituição não deve ser entendida como um ente disperso no sistema jurídico, tampouco pode ser considerada substitutiva da atividade interpretativa. A Constituição seria, assim, a materialização da ordem jurídica do contrato social direcionando para a realização da ordem política e social de uma comunidade. A partir disso, há de se ter consciência de que os princípios são deontológicos e governam a Constituição, o regime e a ordem jurídica. Não seria apenas a lei, "mas o direito em toda a sua extensão, substancialidade, plenitude e abrangência" (STRECK, 2014, p. 345).

Até o início de século XX, mais especificamente até o início da Segunda Guerra Mundial, prevalecia uma cultura baseada na lei aprovada pelo parlamento como fonte principal, relegando às constituições um papel meramente programático, que deveria inspirar a atuação do 
legislador. Desse modo, a norma constitucional não tinha reconhecida uma força normativa que pudesse ser invocada perante o Poder Judiciário. Os direitos fundamentais, para terem validade, deveriam ser protegidos por lei, o que muitas vezes fazia com que predominasse o arbítrio das maiorias instaladas no parlamento (SARMENTO, 2009).

Tal quadro transformou-se substancialmente após esse período, pois a percepção de que as maiorias políticas podem perpetrar ou acumpliciar-se com a barbárie, como ocorreu com o nazismo, levou as novas constituições a criarem ou fortalecerem a jurisdição constitucional, instituindo potentes mecanismos de proteção dos direitos fundamentais, inclusive em face do legislador (SARMENTO, 2009).

Assim, a reconstitucionalização da Europa, ao longo da segunda metade do século XX, redefiniu o lugar da Constituição e a influência do direito constitucional sobre as instituições contemporâneas. A principal referência no desenvolvimento do novo direito é a Lei Fundamental de Bonn (Constituição Alemã) de 1949 e a criação do Tribunal Constitucional Federal em 1951. A partir desse momento, iniciou-se uma incessante produção científica e doutrinária acerca do Direito Constitucional nos países de tradição romano-germânica. No Brasil, esse processo intensificou-se com a aprovação da Constituição de 1988, garantindo a consolidação de um Estado Democrático de Direito com relativa estabilidade (BARROSO, 2005).

Segundo Hesse (1991), a Constituição Jurídica está condicionada pela realidade histórica e não pode ser separada da realidade concreta de seu tempo - e isto tem que ser levado em conta para satisfazer a sua pretensão de eficácia. Ela mesma converte-se em força normativa que influi e determina a realidade política e social. Constata-se os limites da força normativa quando há uma mudança nos fatores do presente.

Se os pressupostos da força normativa encontrarem correspondência na Constituição, se as forças em condições de violá-la mostrarem-se dispostas a render-Ihe homenagem, se, também em tempos difíceis, a Constituição lograr preservar a sua força normativa, então ela configura verdadeira força viva capaz de proteger a vida do Estado contra as desmedidas investidas do arbítrio. Não é, portanto, em tempos tranquilos e felizes que a Constituição normativa vê-se submetida à sua prova de força. Em verdade, esta prova dá-se nas situações de emergência, nos tempos de necessidade. (HESSE, 1991, p. 25).

Em se tratando de uma norma que cria o estado, suas instituições e protege direitos, a Constituição deve ter um aparato de proteção contra eventuais tentativas de enfraquecimento. Nesse caso, o autor destaca o fato de que a própria força normativa pode vir a ser testada em momento de excepcionalidade, em que venha a se argumentar pela necessidade de relativizar seus comandos por alguma razão. Nesses períodos, a Constituição pode vir a ser testada, e é nessas ocasiões que a sua força deve ser afirmada.

Em determinada medida, reside aqui a relativa verdade da conhecida tese de Carl Schmitt segundo a qual o estado de necessidade configura ponto essencial para a caracterização da força normativa da Constituição. Importante, todavia, não é verificar, exatamente durante o estado de necessidade, a superioridade dos fatos sobre o significado secundário do elemento normativo, mas, sim, constatar, nesse momento, a superioridade da norma sobre as circunstâncias fáticas. (HESSE, 1991, p. 25).

$\mathrm{Na}$ esteira do período de fortalecimento da Constituição no período pós-guerra, consolidou-se o denominado Neoconstitucionalismo, caracterizado, principalmente, pelo reco- 
nhecimento da força normativa dos princípios, pela rejeição ao formalismo, pelo recurso a métodos abertos de interpretação, pela constitucionalização do direito e pela irradiação das normas de direitos fundamentais para todos os ramos (SARMENTO, 2009).

Outra característica marcante é o foco no Poder Judiciário, em que o juiz é concebido como um guardião das promessas civilizatórias dos textos constitucionais. Dessa maneira, os membros do Poder Judiciário assumiriam um protagonismo no que se refere à interpretação das normas constitucionais, em detrimento dos demais poderes, fato que acaba por se tornar controvertido em razão dos limites dessa atividade interpretadora e da possibilidade do exercício de um ativismo judicial (SARMENTO, 2009).

A origem do ativismo judicial remonta ao período da grande crise de 1929, quando a Suprema Corte norte-americana foi obrigada a decidir diversos casos envolvendo o New Deal. A partir da década de 1950, a Suprema Corte passou a produzir jurisprudência progressista em matéria de direitos fundamentais (BARROSO, 2012). Após isso, a Suprema Corte americana, assumiu um papel de protetora dos direitos fundamentais, sobretudo de grupos minoritários, quantitativamente ou representativamente, como as minorias raciais.

Assim, a noção de ativismo judicial está ligada a uma participação mais ampla do Judiciário na concretização dos valores e fins constitucionais, com uma maior atuação no espaço dos demais poderes. A postura ativista manifesta-se, por exemplo, por meio da aplicação direta da Constituição a situações não contempladas expressamente em seu texto e sem manifestação do legislador, declaração de inconstitucionalidade em situação em que ela não seja ostensiva e imposição de condutas ou de abstenções ao Poder Público (BARROSO, 2012).

Ao proteger esses interesses da minoria, o Judiciário exerce a sua função contramajoritária. De tal forma, em certas situações, determinado grupo de indivíduos ou, até mesmo, toda a coletividade pode ficar à mercê de sofrer restrições na fruição de seus direitos mais básicos, o que, muitas vezes, ocorre sob um manto de legalidade.

\section{O ESTADO DE EXCEÇÃO}

O estado de exceção é normalmente identificado como um instituto relacionado a momentos transitórios de alteração da ordem institucional estabelecida por um Estado de Direito. Geralmente, é associado a medidas que permitem ao Estado agir de forma a corrigir uma ameaça ou violação à ordem constitucional.

François Saint-Bonnet alude a duas acepções do vocábulo "exceção". A primeira, denominada por ele de clássica, consistiria no momento durante o qual regras jurídicas previstas para período de "calma" são transgredidas ou suspensas para o enfrentamento de um determinado perigo. Já a segunda, que teria por grande representante Giorgio Agamben, apontaria para uma modificação profunda de certos sistemas jurídicos diante de perigos duráveis, como o terrorismo. Essa última, conforme Saint-Bonnet, não deve perdurar, pois a ideia de um "estado de exceção permanente" constituiria uma contradição, na medida em que exceções se tornariam regras (VALIM, 2018). 
Nesse contexto, no Direito Constitucional, sob os mais variados rótulos, "estado de urgência", "estado de emergência", "estado de sítio", "ditadura constitucional" e "governo constitucional de crise", a exceção é entendida como feixe de prerrogativas de que se vale o Poder Executivo para enfrentar situações anômalas, como uma grave crise institucional ou calamidades de grandes proporções. Destaca-se, ainda, a definição sob o prisma filosófico em que se encontra a clássica afirmação de Carl Schmitt, segunda a qual "soberano é quem decide sobre o estado de exceção" (VALIM, 2018, p. 21). O soberano seria o único capaz de tomar a última decisão, que tem por objeto a situação de exceção.

Carl Schmitt, por sua vez, foi um dos principais teóricos do estado de exceção. Sua teoria começou a ser desenvolvida nas obras A ditadura e Teologia política. Demonstrando fascínio pelo tema, o autor chega a afirmar que a exceção é mais interessante do que o caso normal, que este nada prova e aquela comprova tudo, a qual não somente confirma a regra, como também esta vive de exceção (ALMEIDA; TORREÃO, 2019).

Para Schmitt, a exceção desempenha elemento central, pois ele entende que somente diante da excepcionalidade pode-se vislumbrar quem é o soberano, uma vez que é justamente este quem decide sobre o estado ou a situação de exceção. Ele faz a defesa de uma decisão que provém da excepcionalidade, não da normatividade, atacando, assim, o limite da atuação do Estado dado pela norma jurídica válida. Uma das justificativas dele era que nenhuma validade normativa poderia se fazer por si mesma e que a validade seria insustentável quando se está diante de uma situação de exceção. Em tal situação, pode-se perceber que a norma jurídica advém de uma ordem normativa concreta que se apresentaria nas situações limite (ALVES; OLIVEIRA, 2012).

Nesse contexto, opinião generalizada entende que o estado de exceção constitui "um ponto de desequilíbrio entre direito público e fato político" (AGAMBEN, 2004, p. 11). Outro pensamento é o de que, se são frutos dos períodos de crise política, devem ser compreendidos nessa seara, e não na jurídica. As medidas excepcionais encontrar-se-iam na situação paradoxal de medidas jurídicas que não podem ser compreendidas no plano do direito, e o estado de exceção apresenta-se como forma legal daquilo que não pode ter forma legal (AGAMBEN, 2004).

Entre os elementos que tornam difícil uma definição de estado de exceção, encontra-se a sua estreita relação com momentos de ruptura institucional, tais como guerras civis, insurreições e resistências. Nesse sentido, cabe explicitar que, logo após assumir o poder, Hitler promulgou, no dia 28 de fevereiro, decreto para a "proteção do povo e do Estado", que suspendia os artigos da Constituição de Weimar relativos às liberdades individuais. 0 decreto nunca foi revogado, de modo que todo o Terceiro Reich pode ser considerado um estado de exceção, o qual durou 12 anos (AGAMBEN, 2004).

O Totalitarismo moderno pode ser definido como a instauração, por meio do estado de exceção, de uma guerra civil legal que permite a eliminação física não só de adversários políticos, mas também de categorias inteiras de cidadãos que pareçam não integráveis ao sistema político. Desde então, a criação de um estado de emergência permanente tornou-se prática comum nos Estados contemporâneos, inclusive nos denominados democráticos (AGAMBEN, 2004). 
Convém destacar que existem diversos estados de exceção, ou seja, parcelas de poder que lícita ou ilicitamente escapam dos limites do estado de direito (BASILIEN-GAINCHE apud VALIM, 2018). Diferentemente do que acontece com um movimento revolucionário, com a exceção não se pretende instaurar declaradamente uma nova ordem constitucional, ela corrói de maneira sub-reptícia o Estado Democrático de Direito. Embora existam aqueles que negam a juridicidade da exceção, qualificando-a como uma realidade meramente política, ao que tudo indica ela pertence ao direito, ressaltando que a norma que a determina jamais suspenderá a si própria (VALIM, 2018).

A respeito dessa questão, Agamben afirma que há uma divisão entre os que procuram inserir o estado de exceção no âmbito do ordenamento jurídico e aqueles que o consideram exterior a esse ordenamento, como um fenômeno essencialmente político. No tocante a isso, assevera que:

Entre os primeiros, alguns - como Santi Romano, Hauriou, Mortati - concebem o estado de exceção como parte integrante do direito positivo, pois a necessidade que o funda age como fonte autônoma de direito; outros como Hoerni, Ranelletti, Rossiter - entendem-no como um direito subjetivo (natural ou constitucional) do Estado à sua própria conservação. Os segundos - entre os quais estão Biscaretti, Balladore-Pallieri, Carré de Malberg consideram, ao contrário, o estado de exceção e a necessidade que o funda como elementos de fato substancialmente extrajurídicos, ainda que possam, eventualmente, ter consequências no âmbito do direito. (AGAMBEN, 2004, p. 38).

O autor questiona mais adiante:

Se o que é próprio do estado de exceção é a suspensão (total ou parcial) do ordenamento jurídico, como poderá essa suspensão ser ainda compreendida na ordem legal? Como pode uma anomia ser inscrita na ordem jurídica? E se, ao contrário, o estado de exceção é apenas uma situação de fato e, enquanto tal, estranha ou contrária à lei; como é possível o ordenamento jurídico ter uma lacuna justamente quanto a uma situação crucial? E qual é o sentido dessa lacuna? (AGAMBEN, 2004, p. 39).

Após realizar esses questionamentos, Agamben (2004) salienta que o estado de exceção não é exterior nem interior ao ordenamento jurídico e o problema da sua definição se refere a um patamar ou a uma zona cinzenta em que, dentro e fora, não se excluem, mas se indeterminam. A suspensão da norma não significa a sua abolição, e a zona de anomia por ela instaurada não é destituída de relação com a ordem jurídica.

Nesse contexto, há um debate interessante acerca do fundamento do estado de exceção. Uma das correntes mais citadas sustenta-se no conceito de necessidade, recorrendo ao adágio latino necessitas legem non habet, que significa "a necessidade não tem lei". Segundo Agamben (2004), isso deve ser entendido em dois sentidos opostos: "a necessidade não reconhece nenhuma lei" e "a necessidade cria sua própria lei".

O autor conclui que o entendimento da estrutura e do significado do estado de exceção pressupõe uma análise do conceito jurídico de necessidade. Entende que a necessidade não é fonte de lei, tampouco a suspende, ela se limita a subtrair um caso particular à sua aplicação literal. Entretanto, aduz que o estado de exceção moderno é, na verdade, uma tentativa de incluir, na ordem jurídica, a própria exceção, criando uma zona de indiferenciação em que fato e direito coincidem. 
Por fim, Agamben (2004) entende que a teoria do estado de necessidade não se sustenta, pois diz respeito à própria natureza da necessidade que alguns autores continuam a pensar, mais ou menos inconscientemente, como uma situação objetiva. De tal maneira, o conceito de necessidade seria totalmente subjetivo, relativo ao objetivo que se quer atingir. François Saint-Bonnet afirma que a questão da exceção no direito público não trata apenas de descartar a legislação aplicável em decorrência de certas circunstâncias, mas também se refere à subtração das relações normais entre governantes e governados (BERCOVICI, 2014).

Sendo assim, grande parte dos constitucionalistas é favorável à constitucionalização da exceção, cujo objetivo seria racionalizar a proteção extraordinária do Estado, incorporando-a ao ordenamento jurídico. Nessa esteira, os poderes excepcionais deveriam ser expressamente previstos na Constituição para possibilitar limitação e controle, inclusive como forma de afirmação da democracia (BERCOVICl, 2014).

Nessa linha, o estado de exceção revelar-se-ia controlável, administrável, se executado da forma disposta nos textos constitucionais e legais. Com base em Godoy (2016, p. 301): "Sua decretação efetiva, no entanto, conduz a abstração conceitual construída na normalidade a uma agressiva e hostil estrutura política e burocrática que viabiliza as mais monstruosas barbáries".

No âmbito nacional, a Constituição Federal de 1988 traz a previsão de medidas excepcionais voltadas para a defesa do Estado e das instituições democráticas. 0 chamado sistema constitucional de crises tem como instrumentos o estado de defesa e o estado de sítio, objetivando a manutenção ou o restabelecimento da ordem em momentos de anormalidade. Portanto, o controle das crises configura-se como um sistema jurídico formado por normas constitucionais que fixam e prescrevem as providências necessárias para solucionar as crises político-institucionais. A excepcionalidade seria a tônica nesses casos, justificando as medidas até que o equilíbrio constitucional seja, novamente, atingido (FERNANDES, 2018).

\section{SITUAÇÓES DE EXCEÇÃO NA HISTÓRIA RECENTE E CONTROLE JUDICIAL}

Após os atentados terroristas praticados em 11 de setembro de 2001, o governo dos Estados Unidos aprovou diversos atos normativos na intenção de reduzir garantias fundamentais em geral, sob o pretexto de enfrentar, com maior rigor, e prevenir atos de terrorismo. No dia 13 de novembro de 2001, aprovou o Military Order, que autorizava detenções por períodos indefinidos, e o processo, perante as Military Commissions, dos não cidadãos suspeitos de envolvimento em atividades terroristas. Posteriormente, em 26 de setembro de 2001, o Senado americano promulgou o Patriot Act, que, entre outras coisas, permitia ao Attorney General manter preso o estrangeiro suspeito de atividades terroristas, que punham em perigo a segurança nacional do país (AGAMBEN, 2004).

Além disso, no prazo de sete dias, o estrangeiro deveria ser expulso ou acusado de violação da lei de imigração ou de algum outro delito. Na hipótese, o ato anulava radicalmente todo estatuto jurídico do indivíduo, produzindo, dessa forma, um ser juridicamente inominá- 
vel e inclassificável. Assim, os talibãs capturados no Afeganistão não gozavam do estatuto de prisioneiros de guerra nos termos da Convenção de Genebra, tampouco de acusados por crimes comuns segundo as leis norte-americanas (AGAMBEN, 2004):

Nem prisioneiros nem acusados, mas apenas detainees, são objeto de uma pura dominação de fato, de uma detenção indeterminada não só no sentido temporal, mas também quanto à sua própria natureza, porque totalmente fora da lei e do controle judiciário. A única comparação possível é com a situação jurídica dos judeus nos Lager nazistas: juntamente com a cidadania, haviam perdido toda identidade jurídica, mas conservavam pelo menos a identidade de judeus. (AGAMBEN, 2004, p. 14).

Em outros momentos, houve essa reclamação de poderes por parte do Poder Executivo, para enfrentar situação de emergência militar ou econômica. Assim ocorreu com a aprovação do New Deal, em que houve uma delegação ao presidente de um poder ilimitado de regulamentação e controle sobre todos os aspectos da vida econômica do país.

É na perspectiva dessa reivindicação dos poderes soberanos do presidente em uma situação de emergência que se deve considerar a decisão do presidente Bush de referir-se constantemente a si mesmo, após o 11 de setembro de 2001, como o Commander in chief of the army. Se, como vimos, tal título implica uma referência imediata ao estado de exceção, Bush está procurando produzir uma situação em que a emergência se torne a regra e em que a própria distinção entre paz e guerra (e entre guerra externa e guerra civil mundial) se torne impossível. (AGAMBEM, 2004, p. 18).

Nessa mesma linha, o governo egípcio, sob o comando do ex-presidente Mohamed Morsi, publicou, em 22 de novembro de 2012, uma declaração constitucional que considerava os decretos presidenciais insuscetíveis de análise judicial e autorizava o presidente a implementar as ações necessárias para proteger o país e os objetivos da chamada Revolução Egípcia, iniciada após a deposição de Hosni Mubarak (MARTINS, 2015).

Em outra situação, em $1^{\circ}$ de maio de 1994, foi aprovado o Decreto n. ${ }^{\circ} 874$, pelo governo da Colômbia, decretando estado de comoção interior e determinando a aplicação de uma legislação especial para os delitos de competência dos juízos regionais, classificados como terrorismo, subversão, sequestro, rebelião, narcotráfico, entre outros. Como exemplo dessa legislação especial, estava o Decreto n. ${ }^{\circ} 2271 / 1991$, que previa liberdade provisória apenas para maiores de setenta anos e aqueles que já tivessem cumprido prisão preventiva, pelo tempo da pena máxima prevista para o crime, na intenção de impedir a incidência da legislação mais favorável nesses casos (MUÑOZ, 2002).

\subsection{A JURISDIÇÃO CONSTITUCIONAL COMO FORMA DE CONTROLE DO ESTADO DE EXCEÇÁO}

Muitas vezes, o próprio sistema constitucional traz a previsão de um sistema de controles por parte dos Poderes Legislativo e Judiciário. Esse controle deve ser exercido sobre os atos que importam suspensão de garantias constitucionais, visando a assegurar que tenham pertinência com a vigência da situação de excepcionalidade. Nessa toada, tanto nos Estados Unidos quanto na Colômbia, as suas respectivas Cortes Constitucionais foram provocadas a exercer controle de constitucionalidade sobre os atos que instrumentalizaram tais medidas, 
adotadas sob a justificativa da necessidade de maior rigor e agilidade por parte das agências do Poder Executivo.

Diante disso, instada a realizar controle de constitucionalidade de declarações de estado de exceção, a Corte Constitucional da Colômbia proferiu decisões importantes (algumas analisadas adiante), no sentido de restringir a utilização de medidas de exceção. Embora não tenha deixado de reconhecer a discricionariedade do Presidente da República para decidir quando e por quanto tempo se deveria utilizar o instituto, a Corte reconheceu a possibilidade de realização de controle de constitucionalidade integral.

Assim, reconheceu-se a inconstitucionalidade de duas declarações de exceção entre 1994 e 1995. Essas decisões resultaram em acusações de "ditadura judicial" por parte da Corte, por supostamente dificultarem o controle da ordem pública pelo governo, diante do contexto do enfrentamento com as Forças Armadas Revolucionárias da Colômbia (FARC), grupo guerrilheiro com atuação no referido país (CAMPOS, 2016).

Nesses precedentes, alguns analisados a seguir, a Corte assegurou que, embora houvesse a faculdade para a decretação de medidas de exceção em qualquer de suas modalidades, tais medidas deveriam observar o princípio da proporcionalidade e jamais poderiam reduzir o núcleo essencial dos direitos fundamentais. Dessa forma, reconheceu a legitimidade desses mecanismos quando previstos na própria Constituição e em documentos internacionais, porém também ressaltou que o controle judicial deve ser ilimitado e permanente (TOBÓN-TOBÓN; MENDIETA-GONZÁLEZ, 2017).

Segundo Muñoz (2002), ex-presidente da Corte Constitucional da Colômbia, a Constituição do referido país consagra três modalidades de estado de exceção, quais sejam, guerra exterior, comoção interna e emergência. 0 autor frisa que o propósito do constituinte é distinguir os cenários de normalidade e anormalidade, deixando claro que esse último se sujeita ao império da norma constitucional.

No dia $1^{\circ}$ de maio de 1994, o governo colombiano aprovou o Decreto n. ${ }^{\circ} 874$, declarando estado de comoção interior, logo após receber uma comunicação do Procurador Geral informando que diversas pessoas acusadas de crimes graves estariam prestes a serem libertadas em virtude do término do prazo para instrução processual. A Procuradoria Geral alegava que não seria possível apreciar o mérito em tais processos dentro do prazo legal e que o atraso poderia resultar na soltura de 724 presos (MUÑOZ, 2002).

Na prática, esse decreto resultaria na manutenção de diversas prisões preventivas sem fundamento legal, enquanto os presos estivessem à espera de julgamento. A Suprema Corte entendeu que o ato seria inconstitucional por ferir direitos de liberdade, a presunção de inocência e a capacidade de autodeterminação da pessoa humana e que não poderia haver uma presunção objetiva de que o investigado, uma vez posto em liberdade, seria uma ameaça à ordem pública (MUÑOZ, 2002).

Em julgamento realizado sob a relatoria do mencionado magistrado integrante da Corte Constitucional colombiana, restou consignado que:

0 argumento que aduz o Governo é absolutamente perigoso, sinaliza a Corte e não demonstra realmente um risco de crise na declaração. Também deve observar-se que o mesmo viola o princípio da presunção de inocência e ataca igualmente os princípios de um estado social de direito que confia em 
suas próprias instituições. A Corte Constitucional considera que neste caso o simples fato de que muitas pessoas saiam das prisões por prescrição do tempo, devido a uma morosidade nos processos, não há um evidente nexo causal com a colocação em perigo das instituições do Estado, nem com a perturbação da ordem pública (COLOMBIA, 1994, p. 1).

No entanto, em outro precedente, na Sentencia n. ${ }^{\circ} \mathrm{C}-556 / 92$, a Corte reconheceu a legitimidade da declaração de estado de comoção, realizando, contudo, um controle do exercício dessa prerrogativa a partir da verificação da presença dos requisitos formais para tanto:

Não obstante, em que pese estas advertências, o Tribunal Constitucional declara a exequibilidade do estado de exceção, com base em duas razões:

a - A certificação dos requisitos formais, quais sejam, o princípio democrático e o de aprovação prévia pelo senado;

b - A adequação dos poderes dados ao Presidente da República, quais sejam, a não existência de poderes ordinários para impedir que ocorra uma crise. (GONZÁLEZ, 2016, p. 148).

A Sentencia $n .{ }^{\circ} \mathrm{C}-802 / 02$ afirmou a legitimidade do controle de constitucionalidade dos atos da seguinte forma:

Em síntese, da Carta Política se infere a competência da Corte Constitucional para realizar o controle de constitucionalidade formal e material tanto dos decretos legislativos declaratórios dos estados de exceção como dos decretos legislativos de execução. Tal competência é corroborada ademais, pelas deliberações que tiveram lugar na Assembleia Nacional Constituinte; pelo modelo de direito constitucional de exceção pelo qual optou o constituinte de 1991; pela regulação que ele fez da natureza, limites e sistema de controle [...]; pela natureza jurídica do decreto declaratório do estado de exceção e pela concepção atual da jurisdição constitucional e de sua função (COLOMBIA, 2002, p. 1).

Além disso, entendeu que seria possível, inclusive, suspender leis que fossem incompatíveis com o estado de exceção, mas não poderiam ser suspensos direitos previstos em tratados internacionais. Nesse sentido:

A Convenção Interamericana de Direitos Humanos e o Pacto Internacional de Direitos Civis e Políticos são os dois instrumentos internacionais que se consideram mais flagrantemente violados. Dentro dos artigos da Convenção Interamericana se destaca o $8^{\circ}$ que indica o seguinte: "Toda pessoa presa ou detida terá direito a ser julgada dentro de um prazo razoável ou ser posta em liberdade". No mesmo sentido, o Comitê de Direitos Humanos da ONU, no caso $n^{\circ} 46$ de 1979, considerou que: "A detenção de um indivíduo por mais de 6 meses antes de que se iniciara o processo, e por mais de dois anos antes de que se pronunciasse a sentença, constituiriam demoras excessivas" (citado pela Corte Constitucional da Colômbia, Sentencia C-556 de 1992). (GONZÁLEZ, 2016, p. 147).

Mesmo reconhecendo a constitucionalidade do estado de comoção, previsto pela ordem constitucional, a jurisdição constitucional atuou para averiguar se o exercício dessa prerrogativa vinha ocorrendo de forma regular. Ainda assim, não admitiu a supressão de direitos e garantias fundamentais considerados núcleos do Estado Democrático de Direito.

Nessa mesma linha, também sob a justificativa de estar enfrentando uma situação de emergência, o governo norte-americano obteve a aprovação do chamado Patriot Act, assi- 
nado pelo presidente George W. Bush em 26 de outubro de 2001. Logo após os ataques terroristas de 11 de setembro, o diploma legal entrou em vigor sob o argumento de empreender um combate ao terrorismo, prevendo uma série de medidas excepcionais a serem conferidas às agências governamentais encarregadas de atuar no combate ao terror.

Críticos do governo Bush argumentaram que essa medida refletia um desprezo pelas liberdades civis básicas. Já apoiadores do governo defendiam que se tratava de uma resposta legislativa apropriada aos ataques terroristas. Em resumo, o ato expandiu bastante os poderes investigativos, ampliando, especialmente, as possibilidades de busca e de atuação na internet, autorizando revistas pessoais clandestinas, a se aproveitarem dos novos padrões estabelecidos pelo Foreign Intelligence Surveillance Act (FISA) (GUIORA; JULIET, 2019).

A referida lei, nos seus diversos capítulos, previa o aumento no financiamento de operações militares e da autoridade do Poder Executivo para o sequestro de ativos financeiros de pessoas, países e entidades estrangeiras suspeitos de participar dos ataques terroristas. Com isso, aumentou a autoridade das agências encarregadas de realizar a vigilância de suspeitos de terrorismo, alterou normas do sistema bancário para combater a lavagem de dinheiro, facilitou a requisição de informações pessoais junto a companhias prestadoras de serviço, facilitou a detenção de suspeitos de terrorismo, além de outras medidas (MORGAN, 2013).

A lei criou, ainda, um tribunal secreto com a função de legalizar, por meio de ordens judiciais, ações dos órgãos de segurança. Esse tribunal chegou a determinar à companhia de telecomunicações Verizon que entregasse à Agência Nacional de Segurança (NSA) e à Polícia Federal norte-americana (FBI) todos os registros telefônicos dos seus clientes, sem que estes fossem alvo de qualquer investigação. A ordem judicial também determinava que a Verizon não divulgasse a existência do pedido e da própria ordem judicial (GREENWALD, 2013). Posteriormente, a Suprema Corte decidiu pela constitucionalidade dessa prática.

Ademais, essa lei permitia que qualquer pessoa no mundo pudesse ser mantida presa por tempo ilimitado, sem uma acusação formal, devido processo e julgamento. Nessa esteira, prisões ilegais e ataques com drones também eram "legalizados" por tribunais secretos, sem qualquer controle, tudo sob a justificativa de estar em guerra contra o terror (MELO, 2013).

Não obstante, muitas ações do governo norte-americano fundadas no Patriot Act foram alvo de questionamento judicial - chegando alguns casos à Suprema Corte em razão das alegações de violação de direitos humanos, como ocorreu no caso Rasul v. Bush, no ano de 2003. Nesse contexto, diversos indivíduos de diferentes nacionalidades foram capturados no Afeganistão e no Paquistão, sob a suspeita de terem laços com organizações terroristas. Após familiares desses prisioneiros ingressarem com pedidos de Habeas Corpus, o governo alegou que a jurisdição federal não poderia conhecer casos em que os detidos de outras nacionalidades estivessem fora do território norte-americano (TAUBER; BANKS, 2019).

Por seis votos a três, a Suprema Corte decidiu que, apesar de a ilha de Guantánamo estar localizada em outro país, os Estados Unidos detinham pleno controle da base naval no território cubano, situação que equivaleria à detenção em solo nacional. Porém, essa decisão, não resultou na soltura dos indivíduos, pois apenas lhes foi garantida a submissão do caso à Jurisdição Federal (UNITED STATES OF AMERICA, 2004a). 
Em outra situação, também no ano de 2004, a Suprema Corte decidiu o caso Hamdi v. Rumsfeld, que se distinguia do mencionado anteriormente por envolver um cidadão norte-americano chamado Yaser Hamdi. Embora nascido na Louisiana, cresceu fora dos Estados Unidos e foi capturado lutando ao lado das forças do Talibã no Afeganistão. Posteriormente, foi levado para a prisão de Guantánamo, quando a sua cidadania foi descoberta, sendo então transferido para uma prisão militar. Inicialmente, foi negado ao preso o direito de se comunicar com um advogado, o que o levou a arguir a violação ao devido processo legal previsto na quinta emenda da Constituição norte-americana (TAUBER; BANKS, 2019).

Dessa forma, alegou estar sendo impedido de contestar a sua prisão por meio de um defensor. O Estado americano, por sua vez, alegava a autoridade exclusiva do presidente para decidir qual prisioneiro seria considerado inimigo combatente e que o princípio da separação de poderes impediria o Judiciário de interferir nessa questão. A Suprema Corte, por seis votos a três, decidiu que o presidente não teria autoridade exclusiva para determinar quando um prisioneiro tem o direito de contestar a sua prisão mediante um defensor. A Justice Sandra Day O'Connor afirmou que, pelo fato de Hamdi ser um cidadão norte-americano, o governo estaria violando o direito ao devido processo legal previsto na quinta emenda, que Ihe asseguraria o direito de contestar a sua prisão (UNITED STATES OF AMERICA, 2004b).

Entretanto, nesse caso, não houve consenso entre os julgadores quanto aos poderes conferidos ao presidente para a detenção de combatentes inimigos. Dois dos Justices, David Souter e Tuth Bader, discordaram no tocante ao entendimento de que a Authorization for Use of Military Force (AUMF) atribuiria esses poderes ao presidente. O Justice Souter, em sua opinion, destacou que discordava dos demais nesse ponto. Enfatizou que o governo não foi capaz de demonstrar que a AUMF assentia a detenção no caso em discussão e que o senhor Hamdi deveria ser libertado imediatamente. Para ele, a AUMF não utiliza a palavra detenção e nenhuma interpretação da lei indica a intenção de conferir autoridade ao presidente para determinar prisão de cidadãos como inimigos combatentes. Aduziu, ainda, que existiria outro estatuto, o Non-Detention Act, de 1971, que proibia expressamente a detenção de cidadãos norte-americanos, exceto com autorização de lei aprovada pelo Congresso (EDELSON, 2017).

No caso Hamdan v. Rumsfeld, julgado em 2006, Salim Hamdan, que havia sido motorista de Osama bin Laden, foi capturado no Afeganistão e transferido para a prisão de Guantánamo, ficando o seu caso sob a tutela de um tribunal militar, que o declarou combatente inimigo. Antes dessa declaração, o Hamdan ajuizou pedido de Habeas Corpus perante um juízo federal, que reconheceu o direito a uma audiência para verificar o status do preso e eventual submissão aos direitos previstos na Convenção de Genebra. Tal decisão foi reformada após apelação, sob o argumento de que o Congresso havia autorizado o julgamento perante as chamadas Comissões Militares e que a Convenção de Genebra não produziria efeitos no solo norte-americano (TAUBER; BANKS, 2019).

O caso foi levado à Suprema Corte, que reformou a decisão por cinco votos a três, prevalecendo o entendimento de que nem a Constituição nem qualquer outra lei autorizaram as Comissões Militares a atuarem dessa forma e de que a Convenção de Genebra deveria ser observada no caso, pois produzia efeitos dentro do território nacional (UNITED STATES OF AMERICA, 2006).

Após esse caso, o Congresso aprovou o Military Comission Act (MCA), que retirava expressamente da jurisdição federal a competência para conhecer Habeas Corpus ajuizados 
por presos de Guantánamo. Assim, no caso Boumediene v. Bush, Lakhdar Boumediene, cidadão argelino capturado na Bósnia, suspeito de planejar ataques a uma embaixada, ajuizou Habeas Corpus visando a contestar a sua prisão, não sendo o writ conhecido pelas instâncias ordinárias com base na limitação imposta no MCA. Diante disso, a Suprema Corte novamente foi provocada a se pronunciar sobre a questão e, por cinco votos a quatro, reformou a decisão inicial (TAUBER; BANKS, 2019).

De tal modo, prevaleceu o entendimento de que o MCA não poderia autorizar que o presidente, por ato próprio, designasse os prisioneiros como combatentes inimigos, ou não. Além disso, reafirmou que a garantia do Habeas Corpus não poderia ser suprimida a despeito de previsões legais, pois isso estaria contrariando a Constituição, que deveria ser respeitada mesmo em situações extraordinárias (UNITED STATES OF AMERICA, 2008).

Cabe ressaltar, nesse último caso, que os Justices que votaram pela improcedência o fizeram sob o entendimento de que a garantia do Habeas Corpus não seria extensível a estrangeiros que apoiam os considerados inimigos da nação. Perante isso, a atuação da Suprema Corte não ficou isenta de críticas. Nesse sentido, Guiora e Juliet (2019) afirmam que sucessivos governos têm adotado medidas que minimizam os direitos individuais. Enquanto isso, Congresso e Suprema Corte falharam em fortalecer e aplicar, com rigor, freios e contrapesos, deixaram de atuar no campo do combate ao terrorismo para deixá-lo totalmente sob o domínio do Executivo. As consequências desse hiato são deletérias aos direitos fundamentais, além de ser questionável se há algum benefício na restrição desses direitos.

\subsection{A PANDEMIA DA COVID-19 COMO MOTIVO PARA DECRETAÇÃO DE ESTADO DE EXCEÇÃO}

No momento atual, o mundo vivencia um estado de completa excepcionalidade em razão de uma pandemia causada pela Covid-19. 0 alto número de pessoas infectadas vem abalando os sistemas de saúde dos mais diversos países em diferentes amplitudes. Alguns países europeus, como a Itália e a Espanha, sofreram um maior impacto por terem a sua capacidade de atendimento médico completamente esgotada. Nesses países, chegou-se ao ponto de se fazer escolhas entre os pacientes que deveriam receber respiradores, por não haver um número suficiente para atender a todos os necessitados.

Diante de muitas incertezas científicas quanto à eficácia de medicamentos, forma de contágio, com o passar dos meses, a experiência internacional demonstrou que, no momento, a única maneira eficaz de interromper a cadeia de contágio seria o isolamento social, com a paralisação completa de quase todas as atividades. Assim, o que se viu, em alguns países, foi uma resistência de parte da população em cumprir determinações de isolamento impostas pelas autoridades.

Nesse cenário de excepcionalidade, com necessidade de impor medidas restritivas aos direitos de liberdade, alguns governos, ao que tudo indica, têm se aproveitado para alterar as respectivas ordens constitucionais, sob a justificativa de que precisam de maiores poderes para tomar medidas visando ao enfrentamento da pandemia.

Um dos casos que ganhou destaque foi o da Hungria, onde o governo ultradireitista de Viktor Orbán conseguiu em 30 de março de 2020, aprovar uma lei que prolonga o estado de 
alarme de forma indefinida, sob o pretexto de combater o novo coronavírus. Detendo a maioria de dois terços do parlamento, o Executivo ganhou poderes extraordinários para governar por decreto, sem estabelecer um limite temporal e sem nenhum controle, inclusive do parlamento (BLANCO, 2020).

Após pressão internacional principalmente de países Europeus, em 16 de junho, o Parlamento retirou os poderes especiais dados ao premiê. Entretanto, a nova norma permite ao chefe do Executivo, decretar sem anuência do parlamento, um estado de emergência de saúde pública, o que permitiria um retorno à situação anterior (LEHOTAY, 2020). O caso da Hungria demonstra como uma situação de caráter excepcional pode ser utilizada para afastar a ordem constitucional e, por conseguinte, pilares democráticos, como a separação de poderes e liberdades fundamentais. Uma das medidas adotadas era a punição, com até cinco anos de prisão, para quem publicasse informações falsas ou distorcidas que "obstruam" a proteção eficaz da população (BLANCO, 2020).

Medida semelhante foi discutida e aprovada na Bulgária, aumentando os poderes do primeiro-ministro Boyko Borisov. Contudo, alguns artigos foram revogados pelo parlamento justamente pelo temor de que a medida pudesse ferir a liberdade de expressão no país. Uma das medidas, a exemplo do que houve na Hungria, previa pena de prisão de até três anos para quem espalhar notícias falsas. 0 presidente Rumen Radev vetou essa parte da lei, alegando que poderia causar mais problemas ao país, uma vez que restringiria o acesso à informação. Filipinas, Índia, Polônia e Áustria também aprovaram medidas dando mais poderes aos respectivos chefes do executivo para combater a pandemia (BRAUN, 2020).

A Itália, país mais afetado pela Covid-19, até o momento, aprovou um decreto-lei por razões de higiene e segurança pública, impondo uma série de restrições, entre as quais: a proibição de afastamento do município por residentes, a proibição de acesso a determinadas áreas, a suspensão de manifestações e qualquer forma de reunião, a suspensão dos serviços educacionais para crianças e adolescentes, além de outras restrições.

Em um artigo publicado em 26 de fevereiro de 2020, bem antes da eclosão da contaminação ocorrida na Itália, Giorgio Agamben chegou a afirmar que tais medidas eram irracionais e totalmente imotivadas e que estaria havendo uma provocação de um estado de exceção. Entretanto, os acontecimentos posteriores levaram o país a entrar em bloqueio total, pois foi a única maneira encontrada para conter a onda de contágio. (AGAMBEN, 2020).

Já no início de agosto, o Parlamento aprovou a extensão dos poderes de emergência ao primeiro-ministro Giuseppe Conte até 15 de outubro. Tais poderes permitem que o governo mantenha as restrições e responda prontamente a novos surtos com as medidas restritivas que julgar adequadas (HOROWITZ, 2020). Até o momento, tudo indica que, no caso italiano, as medidas realmente foram adotadas para perdurar temporariamente e apenas com 0 intuito de conter o avanço da doença.

Já na Alemanha, a Corte Constitucional Federal rejeitou pedidos realizados contra as medidas de restrição a reuniões de pessoas em geral, impostas aos cidadãos da região da Bavária. A alegação era de restrição a direitos fundamentais de liberdade que estavam sendo limitados demasiadamente e de que não mais subsistiria razão para tanto. A Corte rejeitou liminarmente o pedido, sob o fundamento de que as restrições não eram infundadas e que guardavam pertinência com os objetivos de preservar a saúde coletiva (GERMANY, 2020). 


\section{CONCLUSÓES}

As Cortes Constitucionais têm o relevante papel de proteger e efetivar a norma constitucional, garantindo a vigência do Estado Democrático de Direito. Assim, a ordem de valores que integram o sistema constitucional continua vigente em qualquer situação que fuja da normalidade, independentemente da sua denominação. Ainda que o próprio sistema constitucional traga uma normatização para atuação em momentos de crise, os valores imanentes à ordem constitucional permanecem plenamente em vigor.

Mesmo em uma situação aceita pelos ordenamentos jurídicos como de emergência, o Poder Judiciário, em qualquer de seus níveis, não deixa de atuar buscando manter um controle da constitucionalidade dos atos praticados na vigência do estado de exceção. Ainda que o sistema constitucional preveja a prerrogativa do Poder Executivo, com a anuência do Legislativo, de atuar com poderes excepcionais, a função judicial de controle não sofre qualquer restrição quanto à função de avaliar a constitucionalidade dos atos praticados.

Dessa forma, por mais que se autorize a tomada de medidas que venham a cercear certas garantias fundamentais, é função das Cortes Constitucionais e da Jurisdição comum, atuarem para controlar tais medidas e, sobretudo, impedir que a situação provisória se torne definitiva, degenerando o instituto. Nos precedentes analisados, ambas as cortes admitem a utilização de medidas excepcionais que restrinjam direitos fundamentais, porém ratificando sempre a possibilidade de verificar a constitucionalidade das medidas utilizadas.

Comparando os casos dos Estados Unidos e da Colômbia, foi possível verificar um grau de tolerância diferenciado no que diz respeito à restrição de garantias fundamentais. A Corte norte-americana adotou, em alguns casos, posição mais restritiva, ao reconhecer, por exemplo, que os presos em Guantánamo tinham direito de ser submetidos à Jurisdição Federal, mas sem reconhecer de imediato a ilegalidade das detenções.

Portanto, conclui-se que o controle judicial pode realizado com maior efetividade nos sistemas constitucionais que aceitam e regulamentam a situação de excepcionalidade. A legitimidade do instituto é reconhecida, em muitos lugares, como uma ferramenta importante e até essencial para o enfrentamento de situações emergenciais ligadas à segurança e à saúde, por exemplo. No entanto, nem todas as constituições preveem a regulamentação do instituto, o que faz com que haja uma margem de discussão maior no que tange à constitucionalidade das medidas de execução, como ocorre nos Estados Unidos.

Nos casos em que não há uma regulamentação da atuação estatal em situações excepcionais, as instituições democráticas podem ficar mais fragilizadas, ficando os cidadãos sujeitos ao arbítrio do Poder Executivo no exercício dos poderes de persecução criminal. A inexistência de uma definição prévia dos limites do poder estatal leva à violação de direitos que podem ser irreversíveis, mesmo após a obtenção de um remédio judicial.

Diante disso, o pleno funcionamento dos demais poderes, durante a execução de medidas de exceção dentro da dinâmica de freios e contrapesos, é essencial para que se mantenha uma vigilância e um controle sobre as ações praticadas sob os auspícios do estado de emergência ou similar. Nesse sentido, em nenhuma hipótese e grau, deve-se permitir uma redução da capacidade judicial de avaliar os atos praticados sob a vigência de um estado de 
exceção. Medidas que subtraiam do Judiciário a possibilidade de sindicar qualquer ato são inconstitucionais em qualquer hipótese, não devendo ser aceitas em nenhuma hipótese.

\section{REFERÊNCIAS}

AGAMBEN, Giorgio. Estado de exceção. Trad. Iraci D. Poleti. São Paulo: Boitempo, 2004.

AGAMBEN, Giorgio. 0 estado de exceção provocado por uma emergência imotivada. Trad. Luisa Rabolini. Revista IHU, São Leopoldo, 27 fev. 2020. Disponível em: http://www.ihu.unisinos.br/78-noticias/596584-o-estado-de-excecao-provocado-por-uma-emergencia-imotivada. Acesso em: 9 abr. 2020.

ALMEIDA, Eneá de Stutz e; TORREÃO, Marcelo Pires. O direito na exceção e o direito na transição: fundamentos excepcionais para uma justiça transicional. Revista de Direito da Universidade de Brasília, Brasília, v. 3, n. 1, p. 113-136, dez. 2019. Disponível em: https://periodicos.unb.br/index.php/revistadedireitounb/article/view/26919. Acesso em: 20 mar. 2020.

ALVES, Adamo Dias; OLIVEIRA, Marcelo Andrade Cattoni. Carl Schmitt: um teórico da exceção sob o estado de exceção. Revista Brasileira de Estudos Políticos, Belo Horizonte, n. 105, p. 225-276, jul./dez. 2012. Disponível em: https://pos.direito.ufmg.br/rbep/index.php/rbep/article/view/P.0034-7191.2012v105p225. Acesso em: 12 mar. 2020.

BARROSO, Luís Roberto. Neoconstitucionalismo e constitucionalização do Direito (o triunfo tardio do direito constitucional no Brasil). Revista de Direito Administrativo, Rio de Janeiro, v. 240, p. 1-42, abr./jun. 2005. Disponível em: http://bibliotecadigital.fgv.br/ojs/index.php/rda/article/view/43618. Acesso em: 14 abr. 2020.

BARROSO, Luís Roberto. Judicialização, ativismo judicial e legitimidade democrática. (Syn)Thesis, Rio de Janeiro, v. 5, n. 1, p. 23-32, 2012. Disponível em: https://www.e-publicacoes.uerj.br/index.php/synthesis/article/ view/7433. Acesso em: 9 abr. 2020.

BERCOVICI, Gilberto. A expansão do estado de exceção: da garantia da Constituição à garantia do capitalismo. Boletim de Ciências Econômicas, Coimbra, v. 57, tomo 1, p. 737-754, 2014. Disponível em: https://digitalis-dsp. uc.pt/bitstream/10316.2/39819/1/A\%20expansao\%20do\%20estado\%20de\%20excecao.pdf. Acesso em: 22 abr. 2020.

BLANCO, Silvia. Por coronavírus, Hungria permite que ultradireitista Orbán governe por decreto indefinidamente. El País, Madri, 30 mar. 2020. Disponível em: https://brasil.elpais.com/internacional/2020-03-30/lei-aprovada-na-hungria-permite-que-orban-amplie-indefinidamente-o-estado-de-alarme-devido-a-pandemia.html. Acesso em: 10 abr. 2020.

BRAUN, Julia. Líderes de extrema direita ampliam poder e erram ao lidar com epidemia. Veja, São Paulo, 26 mar. 2020. Disponível em: https://veja.abril.com.br/mundo/lideres-de-extrema-direita-ampliam-poder-e-erram-ao-lidar-com-epidemia/. Acesso em: 28 mar. 2020.

CAMPOS, Carlos Alexandre de Azevedo. Estado de coisas inconstitucional. Salvador: Juspodivm, 2016.

COLOMBIA. Corte Constitucional. Sentencia no. C-300/94. Bogotá: Corte Constitucional, 1994. Disponível em: https://www.corteconstitucional.gov.co/Relatoria/1994/C-300-94.htm. Acesso em: 20 abr. 2020.

COLOMBIA. Corte Constitucional. Sentencia no. C-802/02. Bogotá: Corte Constitucional, 2002. Disponível em: <https://www.corteconstitucional.gov.co/Relatoria/2002/C-802-02.htm>. Acesso em: 20 abr. 2020.

EDELSON, Chris. The hollowing out of Youngstown sheet: how congress and the courts can restore limits on presidential power. In: SPSA ANNUAL MEETING, 88., 2017, New Orleans. Abstract... New Orleans: SPSA, 2017. Disponível em: https://papers.ssrn.com/sol3/papers.cfm?abstract_id=2895076. Acesso em: 7 jul. 2020.

FERNANDES, Bernardo Gonçalves. Curso de Direito Constitucional. 10. ed. Salvador: Juspodivm, 2018. 
GERMANY. Federal Constitutional Court. Unsuccessful applications for preliminary injunctions in relation to the COVID-19 pandemic. Press Release, Karlsruhe, n. 23, abr. 2020. Disponível em: https://www.bundesverfassungsgericht.de/SharedDocs/Pressemitteilungen/EN/2020/bvg20-023.html. Acesso em: 20 abr. 2020.

GODOY, Arnaldo Sampaio de Moraes. O estado de exceção na experiência constitucional brasileira. Revista de Estudos Constitucionais, Hermenêutica e Teoria do Direito, São Leopoldo, v. 8, n. 3, p. 286-302, set./dez. 2016. Disponível em: http://revistas.unisinos.br/index.php/RECHTD/article/viewFile/rechtd.2016.83.03/5716. Acesso em: 10 abr. 2020.

GONZÁLEZ, Clara María Mira. Los estados de excepción en Colombia y aplicación del principio de proporcionalidad: un análisis de seis casos representativos. Opinión Jurídica, Medellín, v. 15, n. 29, p. 141-163, jun. 2016. Disponível em: http://www.scielo.org.co/scielo.php?script=sci_arttext\&pid=S1692-25302016000100008\&lng=en \&nrm=isso. Acesso em: 14 abr. 2020.

GREENWALD, Glenn. NSA collecting phone records of millions of Verizon customers daily. The Guardian, Londres, 6 jun. 2013. Disponível em: https://www.theguardian.com/world/2013/jun/06/nsa-phone-records-verizon-court-order. Acesso em: 14 abr. 2020.

GUIORA, Amos; JOLIET, Chelsea. Counter-terrorism policies and challenges to human rights and civil liberties: a case study of the United States of America. In: SHOR, E.; HOADLEY, S. (eds.). International human rights and counter-terrorism. Singapore: Springer Nature, 2019. p. 293-322. Disponível em: https://link.springer.com/ referenceworkentry/10.1007\%2F978-981-10-4181-5_24\#citeas. Acesso em: 13 maio 2020.

HESSE, Konrad. A força normativa da Constituição. Trad. Gilmar Ferreira Mendes. Porto Alegre: Sérgio Antônio Fabris, 1991.

HOROWITZ, Jason. Cómo logró Italia contener la calamidad del coronavirus. The New York Times, Nova lorque, 6 ago. 2020. Disponível em: https://www.nytimes.com/es/2020/08/05/espanol/mundo/italia-reapertura-coronavirus.html. Acesso em: 16 ago 2020.

LEHOTAY, Orsolya. Hungary's Democracy Is Still Under Threat. Foreignpolicy, Washington, 17 jul. 2020. Disponível em: https://foreignpolicy.com/2020/07/17/hungary-democracy-still-under-threat-orban-state-public-health-emergency-decree/. Acesso em: 16 ago 2020.

MARTINS, Lucas Moraes. Estado de exceção: origem e estrutura topológica. Interthesis, Florianópolis, v. 12, n. 1, p. 157-175, jan./jun. 2015. Disponível em: https://periodicos.ufsc.br/index.php/interthesis/article/view/1807-1384.2015v12n1p157. Acesso em: 15 mar. 2020.

MELO, João Ozório. Americanos já acusam perda de garantias constitucionais. Conjur, São Paulo, 9 jun. 2013. Disponível em: https://www.conjur.com.br/2013-jun-09/americanos-sentem-perda-garantias-constitucionais-guerra-terror. Acesso em: 12 abr. 2020.

MORGAN, Andrew. The patriot act and civil liberties. Jurist, Pittsburgh, 20 jul. 2013. Disponível em: https://www. jurist.org/archives/feature/the-patriot-act-and-civil-liberties/. Acesso em: 15 abr. 2020.

MUÑOZ, Eduardo Cifuentes. Los estados de excepción constitucional en Colombia. Ius et Praxis, Talca, v. 8, n. 1, p. 117-146, 2002. Disponível em: https://scielo.conicyt.cl/scielo.php?script=sci_arttext\&pid=S0718$-00122002000100009 \&$ Ing=es\&nrm=iso. Acesso em: 14 abr. 2020.

SARMENTO, Daniel. O neoconstitucionalismo no Brasil: riscos e possibilidades. 2009. Disponível em: https:// www.passeidireto.com/arquivo/3526139/neoconstitucionalismo-no-brasil-riscos-e-possibilidades. Acesso em: 11 mar. 2020.

STRECK, Lenio. A hermenêutica jurídica $e(m)$ crise: uma exploração hermenêutica da construção do Direito. 11. ed. Porto Alegre: Livraria do Advogado, 2014.

TAUBER, Steven; BANKS, Christopher. Civil rights and liberties with national security: the role of the federal judiciary. In: SHOR, E.; HOADLEY, S. (eds.). International human rights and counter-terrorism. Singapore: Springer Nature, 2019. p. 451-471. Disponível em: https://link.springer.com/referenceworkentry/10.1007/978-981-10-4181-5_24. Acesso em: 16 jun. 2020. 
TOBÓN-TOBÓN, Mary Lu; MENDIETA-GONZÁLEZ, David. Los estados de excepción en el régimen constitucional colombiano. Opinión Jurídica, Medellín, v. 16, n. 31, p. 67-88, set. 2017. Disponível em: https://revistas.udem.edu. co/index.php/opinion/article/view/2170/1868. Acesso em: 20 abr. 2020.

UNITED STATES OF AMERICA. Supreme Court. Hamdi v. Rumsfeld. In: UNITED STATES OF AMERICA. Supreme Court. United States Reports: United States Reports: cases adjudged in the Supreme Court at October Term, 2003. Washington, DC: Supreme Court, 2004a. 542 v. p. 507-599. Disponível em: https://www.supremecourt.gov/opinions/boundvolumes/542bv.pdf. Acesso em: 5 maio 2020.

UNITED STATES OF AMERICA. Supreme Court. Rasul v. Bush. In: UNITED STATES OF AMERICA. Supreme Court. United States Reports: cases adjudged in the Supreme Court at October term, 2003. Washington, DC: Supreme Court, 2004b. 542 v. p. 466-506. Disponível em: https://www.supremecourt.gov/opinions/boundvolumes/542bv. pdf. Acesso em: 5 maio 2020.

UNITED STATES OF AMERICA. Supreme Court. Hamdan v. Rumsfeld. In: UNITED STATES OF AMERICA. Supreme Court. United States Reports: cases adjudged in the Supreme Court at October term, 2005. Washington, DC: Supreme Court, 2006. 548 v. p. 557- 734. Disponível em: https://www.supremecourt.gov/opinions/boundvolumes/548bv. pdf. Acesso em: 15 abr. 2020.

UNITED STATES OF AMERICA. Supreme Court. Boumediene v. Bush. In: UNITED STATES OF AMERICA. Supreme Court. United States Reports: cases adjudged in the Supreme Court at October term, 2007. Washington, DC: Supreme Court, 2008. 553 v. p. 723-850. Disponível em: https://www.supremecourt.gov/opinions/boundvolumes/553bv. pdf. Acesso em: 10 abr. 2020.

VALIM, Rafael. Estado de exceção: a forma jurídica do neoliberalismo. São Paulo: Conta Corrente, 2018.

Recebido/Received: 23.07.2020.

Aprovado/Approved: 26.09.2020. 